\title{
IOT Based Future Technologies and Developments in Agriculture
}

\author{
Dr. S. Saraswathi ${ }^{1}$, P. Aravindhan ${ }^{2}$, L. Boovesh ${ }^{3}$, V. Sureshkumar ${ }^{4}$ \\ ${ }^{1}$ Associate Professor, Department of Electronics and Communication Engineering \\ ${ }^{2,3}$ UG Scholar, Department of Electronics and Communication Engineering \\ ${ }^{4} U G$ Scholar, Department of Information Technology \\ Mahendra Engineering College (Autonomous), Namakkal, Tamilnadu- 637503, India \\ smartaravindhan777@gmail.com ${ }^{2}$
}

\begin{abstract}
In our future, smarter agriculture are mostly adopted by five technologies. The development of IOT based smart farming will be challenged day by day to turn-over the face of agriculture production and also it enhance to making it cost-effective and reduced the wastage. We are planned to use this five type of technologies and also with their help of sensor to make agriculture smarter and easier to get a rapid growth production. This technology can be applicable to implement in their effective manner to growth in larger production. In 2018, the connected agriculture market stood at USD 1.8 billion globally and the change has not stopped yet. It is expected to grow up to USD 4.3 billion by 2023 at a Compound Annual Growth Rate (CAGR) of 19.5 billion.
\end{abstract}

Keywords: IoT in agriculture, IoT implementation, Smart irrigation system, Autonomous green house.

\section{Introduction}

In our country, population growth has been increased rapidly. We are planned to make a new revolution of these problems to implementing this five techniques to refer the growth level of plants, strength, climatic condition, nutrition level and also collected the data by using IOT and cloud computing technologies. It helps to measure the plants rates and their efficiency. In the next several years, the use of smart solutions powered by IOT will increase in the agriculture operations. In fact, few of the recent report tells that the IOT device installation will see a compound annual growth rate of $20 \%$ in the agriculture industry. While this connected devices (agricultural) will grow from 13 million in 2014 and 225 million in 2024. It can reduce the manual labour work and also collecting the agriculture data to reduce the manual work. Smarter agriculture can be increased by our traditional crops like rice, wheat and sugarcane. We are aiming to increases the crop production by using different types of technologies and also it is useful for our future generations. Global population will be increased 9 billion in 2050 so, we planned to develop this technique to enhance our agriculture crops and also it will be enhance the agriculture industry. These techniques have been used to reduce the environmental issues to make a good revolution. It will be increase the global food management and also it can be reduce the demands of agriculture. While this technique can make a good revolution to completed successfully.[1-4]

\section{Implementation of IOT Technologies in Agriculture:}


1. Climatic condition.

2. Precision farming.

3. Smart green house.

4. Data analytics.

5. Agricultural drones.

\subsection{Climatic Condition}

Climatic conditions are the major role for this theme to increase our crop production. It has been helped to identify the quantity and quality of crops production. While this climatic condition will be enable to measure the real time status with the help of sensors to place both inside and outside, can identify the season growth of production. This climatic condition will detect the temperature, humidity and rainfall. It can set an alarms to check the weather conditions and also it can be used to avoid the reap plants in agricultural production.

Climate change can disturb food availability, reduce way in to food and affect the food quality. [5-9]

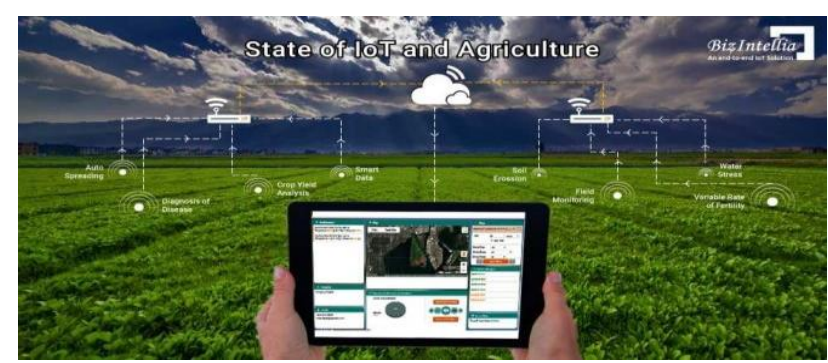

Fig.1. Climatic condition

\subsection{Precision Farming:}

Precision farming is the famous application of these technologies. It can be making as a livestock monitoring, vehicle tracking, field observations and inventory monitoring. In this aim of this farming is used to analyze the data very quickly with good decision. It can be plays a vital role to analyze the soil conditions, measure the water level and nutrient level. In this method, can make precision farming as a precious farming.

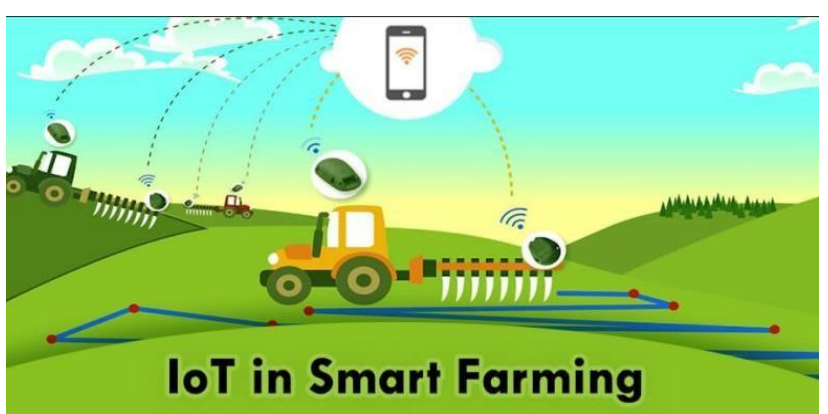

Fig.2. Precision farming

\subsection{Smart Green House:}

Smart green house has been enables to detect the climatic conditions instantly to given a particular instruction. In adaptation of these technologies, green house has been eliminated the human intervention and also it make a costlier efficiency. It can collect the data from the green house by using sensor very precisely. While this technique can send the information through via email or SMS alerts.[10-12]

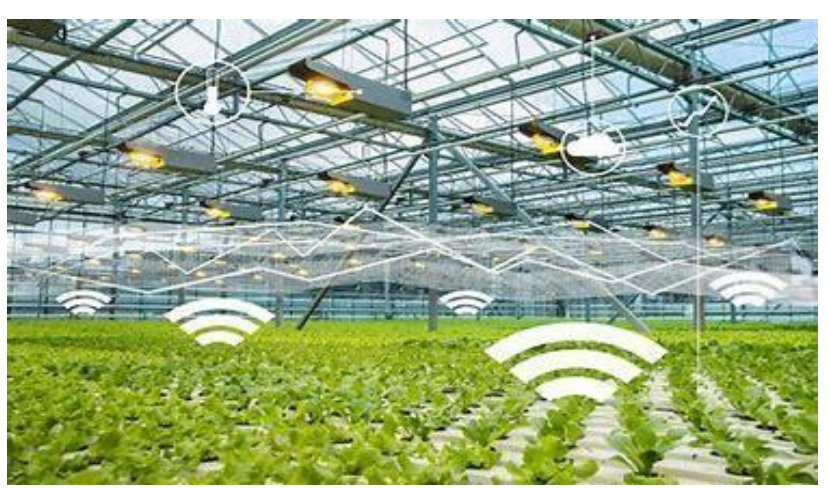

Fig.3. Smart greenhouse

\subsection{Data Analytics:}

Data analytics is the process of collecting the raw data to transfer into the modelling data's into an information. In this scope of database, system was support less amount of storage in internet of things. So we can add the cloud computing technology to analyze the real time crop production and also capturing large amount of 
data. In their trends, analyzes to know the harvesting period and also it knows their quality of crops. We can know the fertility and also volumes of the lands quality.

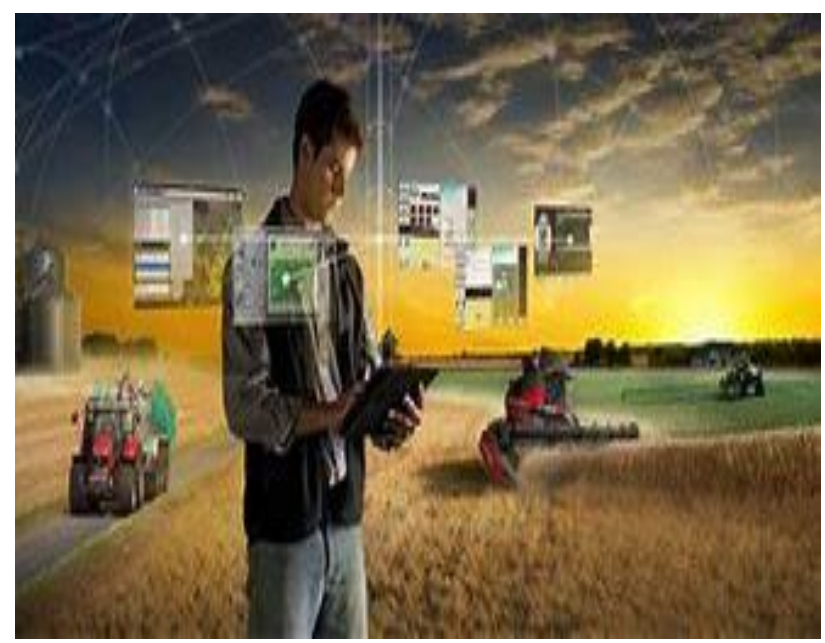

Fig.4. Data analytics

\subsection{Agricultural Drones:}

Agricultural drone is the most advance application of these trending technologies. Aerial drones are used for crop monitoring planting, spraying and field analysis. Drone technology can give the proper strategy in agricultural industry. Drones have multispectral sensors to identify the changes in irrigation and also it calculates the vegetation index and reduces the environmental impact.

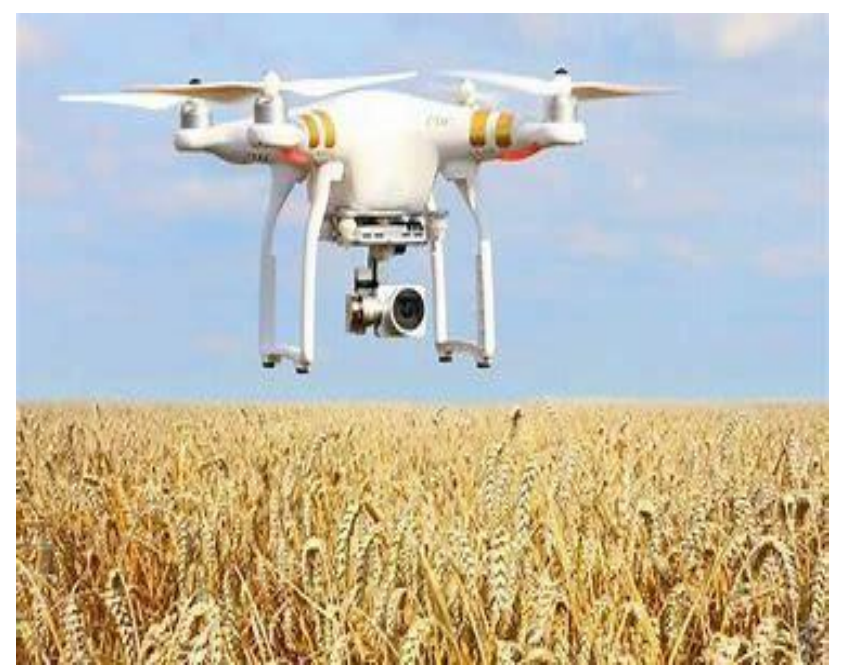

Fig.5. Agricultural drone

\section{Future of IOT in Agriculture:}

In our future, IOT can change the humanity and also changes the whole planet of the earth. It will monitor the soil deteriorating. This technology can be used to predict our future because 9 billion peoples will be increased in 2050. This is the best method to manage our future generations.

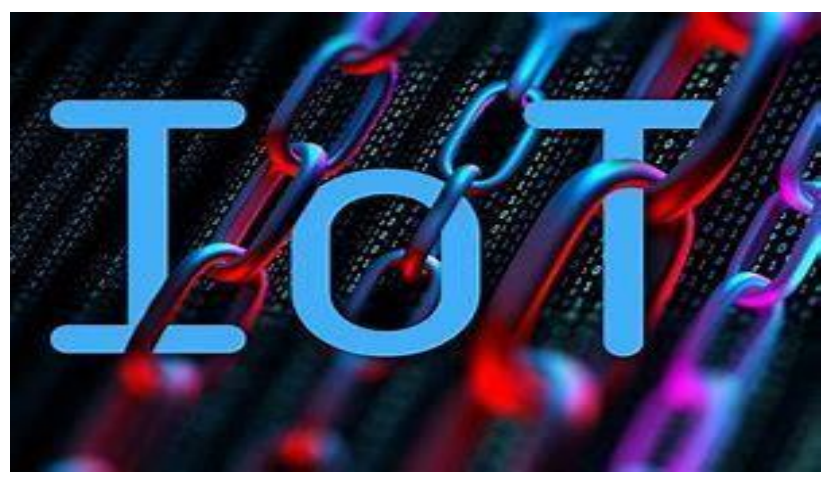

Fig.6. Internet of Things

\subsection{Automated Irrigation System}

Automated irrigation system can be used different types of equipment like soil moisture temperature sensors and electrical conductivity to make the automated irrigation process. In this, systems are optimized to use wireless sensors to develop the agriculture crops and also to maintain the root zone of plants. The additions of these techniques are used for different networks and web applications for maintaining the soil moisture and also threshold temperature.

These techniques can be used to maintain the quantity and quality of soil moisture by using a microcontroller. Recent days, we are facing major problems of water demands and it will be reduced. Automated irrigation can helps to maintain the water level in lands and also it can growth fresh vegetables and fruits. It can be provided the information from Zig-bee to Arduino. While this technique can grower efficiently to increase our economical growth production. 


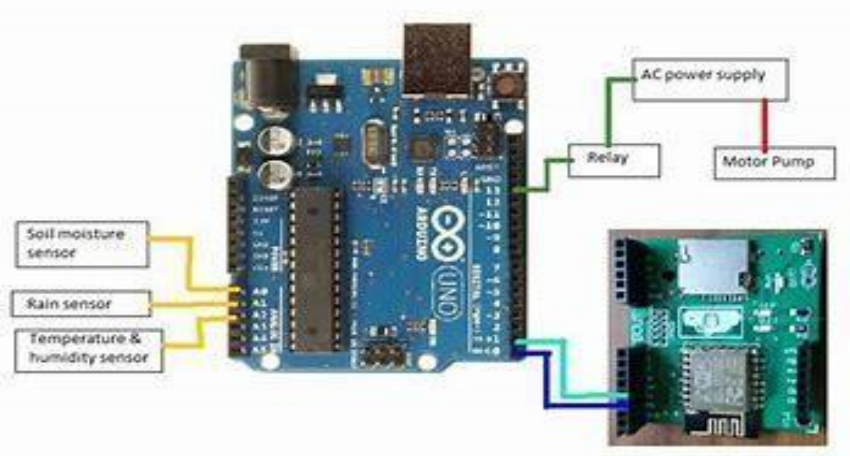

Fig.7. Circuit blocks for automated

\section{Irrigation system \\ 3.2 Autonomous Green House:}

Autonomous green house will be applicable to Netherlands because it is a low land and has less human population in their country. However this IOT technology can be possible in our country to make a bright future for our future generations. In their majority of farm lands are covered with a glass to grow fruits and vegetables by using autonomous green house.

This technology uses sensors to monitor the LED lights Carbon-dioxide level humidity and analysis the data to make a sustainable environment. This technology are mainly adopted with hydroponic and aeroponics to make a larger crop growth production. While these techniques can develop a large amounts fruits and vegetables with a good nutrition and also it can build the future of IOT in agriculture.

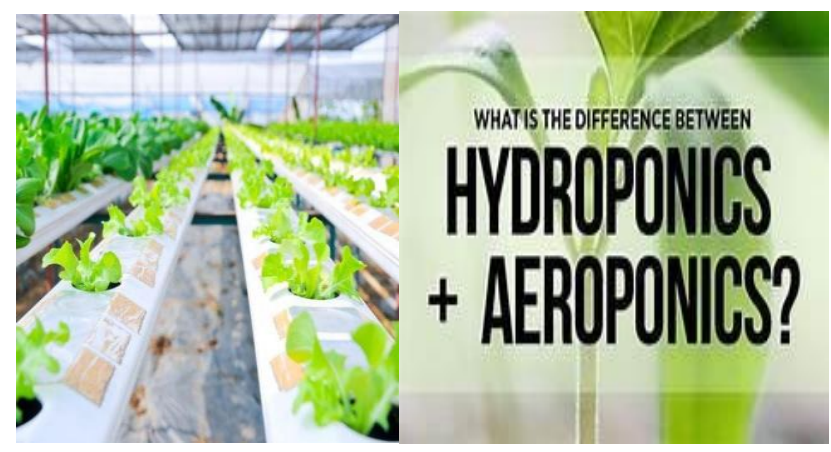

Fig.8. Autonomous green house

\section{IOT Challenges in Agriculture:}

1. Smarter agriculture system can change the whole Industry and also process the traditional growth of our country.
2. It makes connectivity to the different types of technology for the development of rapid growth in agriculture.

3. It has a certain designing and durability to maintaining crop growing level and it can be monitored.

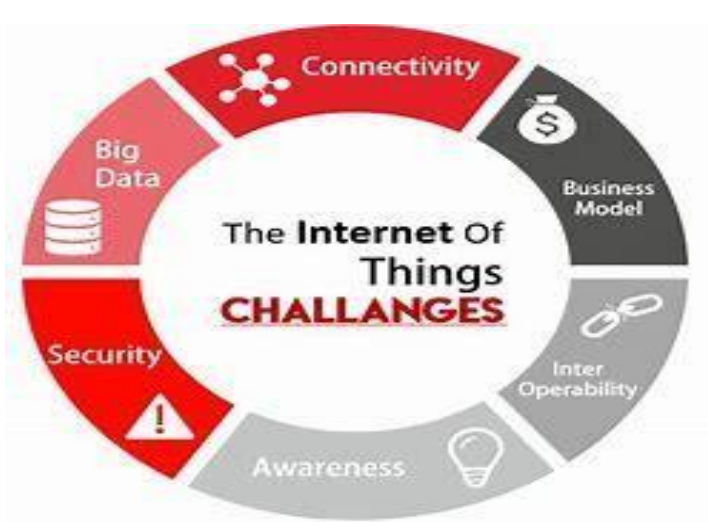

Fig.9. IoT challenges

\section{Benefits of Smart Farming:}

1. This technology can be used to increase the crop production to be faster and earlier with a good efficiency.

2. In business efficiency, these smart devices can be helpful to maintain the standard crop quality.

3. It can be used to monitor the crop strength and also it can maintain with hardware systems to be possible in reliability of life.

4. This farming system has communications through server and data.

5. These five applications are very helpful to farmers to give larger production in an easier way and also it can be distributed and transport faster in supermarkets.

\section{Advantages of IOT:}

1. IOT systems can manage the water content efficiency and also maintain the crop growth.

2. It can be used to save the modern life time to make a smarter agriculture and also reduce the agriculture issues due to humidity rainfall and temperature.

3. It can be used to reduce the manual works and also make a very effective farming to 
maintain the soil managements.

\section{Drawbacks of IOT:}

1. It cannot contain the internet continuously and also network requirements to be faster to fulfill these techniques.

2. It is very complicated to design because it is costlier.

3. It has a several kinds of security issues to maintain these types of networks.

\section{Conclusions}

These agricultural technologies are implemented to encourage the faster rapid growth production and also to fill their gap between quantity and quality. It can be ensured to reduce their crop damages and also seem less to improve the production in agricultural field. This fifth revolution can be step up into a sixth revolution. While this revolution can makes best theme of these content. Innovative applications of IOT can be face enormous challenges in agriculture. It can be increased the quality and quantity of agricultural productions. These techniques can be applied in agriculture to reduce our drought and famine.

\section{References}

[1]. Kaviya, A, Vigneshvwaran, R, \& Leela, M, (2017), Smart Farming Based On Cloud Computing, 3(10), 1-5.

[2].Kerns, S. C, \& Lee, J, (2017), Automated Aeroponics System Using IoT for Smart Farming, $7-$ https://doi.org/10.19044/esj.

[3]. Kote, D, (2015), Internet of Things, Bus INF Syst Eng, 57(3)(8), 221-224. https://doi.org/10.1002/dac.2417

[4]. Kothiya, R. H, (2018), Smart Farming using Internet of Things, 13(12), 1016410168.

[5].Malavade, V. N, \& Akulwar, P.K, (2016), Role of IoT in Agriculture, 56-57.

[6]. Mingze Wu, Yitong Wang, Z. L, (2013), A
New Shelf Life Prediction Method for Farm Products Based on an Agricultural IOT, Advanced Materials Research, 846847, 1830-1835.

[7].]https://www.researchgate.net/publication/ 313804002_Smart_farming_IoT_based_sm art_sensors_agriculture_stick_for_live_tem perature_and_moisture_monitoring_using Arduino_cloud_computing_ solar technology.

[8].https://www.researchgate.net/publication/2 27172798_A_Study_on_Internet_of_Thing s_based_Applications.

[9].https://www.irjet.net/archives/V3/i11/IRJE T-V3I11154.pdf.

[10].https://www.agrifarming.in/future-of-iotin-agriculture-inindia-iot-challengesbenefits.

[11].https://www.iotforall.com/iotapplications-in-agriculture.

[12].https://www.educba.com/iot-inagriculture. 